\title{
Hematoprotective and Gastroprotective Effects of Cnidoscolus aconitifolius (Linn)-Supplemented Diet in Male Wistar Rats
}

\author{
Samuel A. Onasanwo ${ }^{1^{*}}$, Olusegun G. Adebayo ${ }^{1,2}$, Omeje U. Nicodemus ${ }^{1}$, \\ Abayomi M. Ajayi ${ }^{3}$, A. Wadioni ${ }^{2}$ and I. Wopara ${ }^{4}$ \\ ${ }^{1}$ Neurosciences and Oral Physiology Unit, Department of Physiology, University of Ibadan, Ibadan, \\ Nigeria. \\ ${ }^{2}$ Neurophysiology Unit, Department of Physiology, PAMO University of Medical Sciences, \\ Port-Harcourt, River State, Nigeria. \\ ${ }^{3}$ Neuropharmacology Unit, Department of Pharmacology, University of Ibadan, Ibadan, Nigeria. \\ ${ }^{4}$ Department of Biochemistry, PAMO University of Medical Sciences, Port-Harcourt, River State,
}

Nigeria.

\begin{abstract}
Authors' contributions
This work was carried out in collaboration among all authors. Author SAO designed the study, performed the statistical analysis, wrote the protocol and wrote the first draft of the manuscript. Authors OGA and OUN managed laboratory experiments and the analyses of the study. Author AMA managed the literature searches and methodology. Author AW managed the literature searches. Author IW managed the analyses of the study. All authors read and approved the final manuscript.
\end{abstract}

Article Information

DOI: 10.9734/ARRB/2020/v35i230194

(1) Dr. Saleha Sadeeqa, Lahore College for Women University, $\frac{\text { Editor(s): }}{\text { Pakistan. }}$

Reviewers:

(1) Simon Bernard Iloki Assanga, Sonora University, Mexico.

(2) Stalin, India.

Complete Peer review History: http://www.sdiarticle4.com/review-history/55882

Original Research Article

Received 30 January 2020

Accepted 04 April 2020

Published 18 April 2020

\section{ABSTRACT}

Aims: Cnidoscolus aconitifolius (CA) is a plant known to possess very high phenolic compound. The study evaluated hematological indices, anti-oxidative properties and gastroprotective potentials of CA leaf-supplemented diet.

Methodology: Male Wistar rats weighing between $80-100 \mathrm{~g}$ were divided into 5 groups of $n=18$. Group 1 animals were fed with normal diet and groups $2-5$ were fed with diets supplemented with $1 \%, 2.5 \%, 5 \%$ and $10 \%$ of $C$. aconitifolius powdered leaves continuously for 4,8 and 12 weeks. 
Hematological indices were examined in the whole blood plasma Malondialdehyde (MDA), Glutathione (GSH), Catalase (CAT) were investigated, and changes in stomach architecture were also examined via histology.

Results: There was a progressive increase in weight gain at different weeks of feeding with Cnidoscolus aconitifolius-supplemented diet (CAD). Malondialdehyde level decreased $(p<0.05)$ significantly in $1 \%$ CAD at 8 weeks of feeding when compared to normal diet group. Glutathione at the 8th and 12th weeks of feeding with $1 \%$ CAD and 10\% CAD significantly $(p<0.05)$ decreased when compared to the group fed normal diet. Catalase activity increased $(p<0.05)$ significantly in $1 \%, 2.5 \%$ and $5 \%$ CAD groups when compared to the group fed normal diet at 4 weeks of feeding. There was increase in haematological indices across all the groups during the weeks of feeding. The microscopic examination of the stomach epithelial layer reveals improvement with no serious damage across all the groups.

Conclusion: Cnidoscolus aconitifolius-supplemented diet moderately improves blood anti-oxidant against oxidative stress and the hematological indices with time. The diet also maintains the structural integrity of the stomach wall without causing any damage.

Keywords: Cnidoscolus aconitifolius-supplemented diet; anti-oxidant; hematological indices; epithelial; phenolic compound.

\section{INTRODUCTION}

Plants such as vegetables are been considered as plant-based foods and have been reported to promote healthy living in humans and animals, and are also important sources of bioactive phytochemicals $[1,2]$. It is an important source of free radical scavenging antioxidants. The common phytonutrients acting as antioxidants in vegetables are vitamins $\mathrm{C}$ and $\mathrm{E}$, the carotenoids, flavonoids and thiol (SH) compounds [3,4]. Vegetables also have been reported to have flavonoids such as quercetin, kaempferol, catechins, and anthocyanidins which are famous for their antioxidant and antiinflammatory health benefits.

Blood disorders and diseases can be dangerous. They can spread rapidly during the circuit of the bloodstream around the body, and impair many functions aided by blood. Most common disorders associated with blood are anemia, blood clots and cancer [5]. Hematological indices have given insight into the production of potential cells by helping to monitor and evaluate the incidence of diseases in animals $[6,7,8]$. Some vegetables have been seen to possess strong hematopoietic property (enhancing the production of new blood cells); reducing osmotic fragility in protein energy malnutrition, and increasing the life span of erythrocytes [9]. Also, it has been reported that minerals like Vitamins $A$ and $\mathrm{C}, \mathrm{Fe}, \mathrm{Zn}$ and $\mathrm{Cu}$ are in abundance in most vegetables, and it was suggested that they may be of a great use in the management of sickle cell disease and other blood relating disorders [8].
Among the myriads of plants used against chronic diseases is Cnidoscolous aconitifolius. Cnidoscolus aconitifolius (Family: Euphorbiaceae) has many names given to it by different people due to its numerous traditional uses, it is commonly known as 'Efo Jerusalem' or 'Efo lyana Ipaja' in South-West Nigeria and in Niger Delta areas of Nigeria where it is known as 'Hospital Too Far' [10]. The English name of this leafy vegetable is 'tree spinach' and colloquially referred to as 'Chaya' [10]. Interestingly, C. aconitifolius can thrive in a wide range of conditions both in arid and rainy regions with little need for care or extra fertility [11]. It is easy to propagate, yet giving a high production per square foot to serve year-round need of nutrients to people especially in remote areas where access to nutritious foods and supplement is difficult $[12,11]$. The vegetable is a rich source of nutrient such as protein. The total percentage of essential amino acids in Cnidoscolus aconitifolius leaf is about $44.80 \%$ and the non-essential amino acid is $55.19 \%$ [13] and due to it rich protein value, it can also be used for animal feed formulation mixed with maize up to $250 \mathrm{~g} / \mathrm{Kg}$ to improve the performance of animal fed on low protein diets [14]. It is rich in vitamins especially the water-soluble vitamins and micronutrients [15]. Cnidoscolus aconitifolius leaves contain high carotene, vitamin $\mathrm{A}$, vitamin $\mathrm{C}$, niacin, riboflavin, and thiamine [11]. The mineral composition of Cnidoscolus aconitifolius leaf is rich in $\mathrm{P}, \mathrm{K}, \mathrm{Na}, \mathrm{Ca}, \mathrm{Mg}, \mathrm{Zn}$ and $\mathrm{Fe}$ [8].

A great number of the therapeutic applications studies have been reported by various researchers. It was discovered to have 
antidiabetic effect [16], antioxidant property [17,10], hematopoietic property [9], hepatoprotective activity [18,19], antimicrobial properties [10,19,20], antifertility activity [6], analgesic and anti-inflammatory properties [21]. The aim of the present study was to investigate the impact of Cnidoscolus aconitifolius supplemented diet on hematological indices, oxidative stress and stomach histology in experimental animals.

\section{MATERIALS AND METHODS}

Reagents: The 5', 5'-dithio-bis (2-nitrobenzoate) (DTNB), thiobarbituric acid (TBA), and trichloroacetic acid (TCA) were products of Sigma Chemicals Co., USA. Other reagents were of analytical grade and the purest quality available.

Experimental animals and grouping: Ninety male Wistar rats $(80-100 \mathrm{~g})$ were used for this study and were obtained from the Central Animal House, University of Ibadan, Ibadan. They were maintained under standard laboratory conditions and housed in well ventilated plastic cages at room temperature $\left(26-28^{\circ} \mathrm{C}\right)$ and relative humidity (60-70\%), light-dark cycles (12 hr/12 $\mathrm{hr})$, respectively. The animals were acclimated for 2 weeks and allow free access to standard diet (Top feeds Ltd, Ibadan, Nigeria). All procedures used for the experimental animals were in accordance with the guidelines of the University of Ibadan Animal Ethical Committee $2017 / 2018$. The animals were divided by weights into 5 groups of $n=18$. Group 1 animals were fed with normal diet and groups 2-5 were fed with diets supplemented with $1 \%, 2.5 \%, 5 \%$ and $10 \%$ C. aconitifolius-powdered leaves. The animals were fed continuously for 4,8 and 12 weeks and body weight taken weekly. Percentage weight gained, oxidative properties, hematological indices and histology of the stomach were determined for each group at 4th, 8th and 12th weeks of feeding.

Collection and identification of plant materials: $C$. aconitifolius leaves were harvested fresh from a domestic vegetable garden in Ojoo, Ibadan, Oyo- State, Nigeria and were identified and authenticated by a taxonomist in the University of Ibadan Herbarium, Ibadan Nigeria (UIH) with voucher number UIH: 22763. The leaves were air-dried at room temperature. The dried leaves were ground to a fine powder using a mechanical grinding machine. The ground powder which was green in color was preserved in sealed polythene containers at room temperature before use.

Feed formulation: Diet were made from commercially formulated feed (Top Feeds, Ibadan, Nigeria) containing crude protein 23.00, fat/oil 6.00 , crude fibre 5.00 , calcium 1.00, available phosphorus 0.40 , lysine 1.20 , methionine 0.50 , salt $(\mathrm{min}) 0.30$, and $\mathrm{kcal} / \mathrm{kg}$ metabolisable energy ( $\mathrm{min})$ 2900. Cnidoscolus aconitifolius leaf supplemented diet (CAD) was formulated to contain $1 \%, 2.5 \%, 5 \%$ and $10 \%$ CAD. $1 \%$ CAD supplemented diet had $1 \mathrm{~g}$ of CA sample mixed with $99 \mathrm{~g}$ of normal diet while 2.5 $\mathrm{g}, 5 \mathrm{~g}$ and $10 \mathrm{~g}$ of the sample was mixed with $97.5 \mathrm{~g}, 95 \mathrm{~g}$ and $90 \mathrm{~g}$ of the normal diet for $2.5 \%$, $5 \%$ and $10 \%$ supplementation, respectively. Supplemented and non-supplemented diets were homogenized using a mixer and made into pellets.

Hematological indices: Blood was collected from the heart of the animal through cardiac puncture. The red blood cells (RBC), Packed Cell Volume (PCV), hemoglobin and other hematological indices such as, lymphocytes, neutrophils, monocytes, eosinophils and basophils were determined. The mean corpuscular hemoglobin concentration (MCHC), mean corpuscular hemoglobin $(\mathrm{MCH})$ and mean corpuscular volume (MCV) were calculated from $\mathrm{RBC}$, hemoglobin $(\mathrm{Hb})$ and packed cell volume (PCV) values [22,23]. The white blood cell (WBC) count wasalso determined [24].

Biochemical analysis: The blood plasma was used for determination of Malondialdehyde (MDA) by thiobarbituric acid reactive species method [25], reduced glutathione (GSH) by Ellman reagent [26] and catalase (CAT) activity was determined using a colorimetric assay based on the yellow complex with molybdate and $\mathrm{H}_{2} \mathrm{O}_{2}$ which was described in detail by Goth [27].

Histopathological examination: To determine the hematoxylin and eosin, the stomach tissue taken were fixed by immersion $4 \%$ paraformaldehyde in $0.1 \mathrm{~mol} / \mathrm{L}$ phosphate buffer ( $\mathrm{pH}:$ 7.2) for 48 hours, dehydrated, embedded in paraffin, cut into consecutive $5 \mu \mathrm{m}$ transverse sections with a microtome and stained with staining solution (hematoxylin and eosin) [28].

Statistical analysis: All the data are presented as Mean \pm Standard Error of Mean (SEM). Statistical analysis was done using one-way analysis of variance (ANOVA) and two-way 
analysis of variance and then followed by Newman-Keuls and Bonferroni post hoc test. All statistical analyses were done by using Prism software, version (Diego, CA, USA). The statistical difference at level $p<0.05$ was considered significant.

\section{RESULTS}

Effect of Cnidoscolus aconitifoliussupplemented diet on the body weight in rats: The rats showed appreciable weight increase. There was significant $(p<0.05)$ increase in weight gained by rats fed with $5 \%$ CAD and $10 \%$ CAD at 8 th and 12th weeks of feeding when compared to normal diets fed rats (Fig. 1).

Estimation of protein concentration in the plasma of Cnidoscolus aconitifoliussupplemented diet fed rats: The results show that plasma protein concentration increased significantly $(p<0.05)$ in rats fed with $1 \%$ CAD at 4 and 8 weeks of feeding, and in rats fed with $5 \%$ and $10 \%$ CAD for 12 weeks when compared to normal diet group respectively (Fig. 2A).

Estimation of Malondialdehyde level in the plasma of Cnidoscolus aconitifoliussupplemented diet fed rats: MDA level shows significantly $(p<0.05)$ decrease in the rat fed with $1 \%$ CAD gat 8 weeks of feeding when compared to normal diet fed rat (Fig. 2B).

Estimation of Glutathione level in the plasma of Cnidoscolus aconitifolius-supplemented diet fed rats: The level of glutathione activity decreases significantly $(p<0.05)$ in the rat fed with $1 \%$ CAD at 8 weeks and those fed $10 \%$ $\mathrm{CAD}$ at 12 weeks of feeding when compared with the normal diet fed rats respectively (Fig. 2C).

Estimation of Catalase level in the plasma of Cnidoscolus aconitifolius-supplemented diet fed rats: The results show that catalase activity increases significantly in the rats fed 1\%, 2.5\% and $5 \%$ CAD when compared with the normal diet fed rats at 4 weeks of administration (Fig. 2D).

Hematological variables of rats fed Cnidoscolus aconitifolius-supplemented diet for 4 weeks: The result shows significantly $(p<$ 0.05 ) increased in platelets in the rats fed $1 \%$ and $2.5 \%$ CAD when compared to the normal diet fed rats (Table 1).

Hematological variables of rats fed Cnidoscolus aconitifolius-supplemented diet for 8 weeks: The WBC significantly $(p<0.05)$ decrease in the rats fed $1 \%$ and $2.5 \%$ CAD when compared to the normal diet fed rats at eight weeks of feeding. There was also a significant ( $p$ $<0.05$ ) decrease of neutrophils in the rats fed $1 \%$ CAD when compared with the normal diet fed rats (Table 2 ).

Hematological variables of rats fed Cnidoscolus aconitifolius-supplemented diet for 12 weeks: The result shows that the eosinophils increased significantly $(p<0.05)$ in the rats fed $1 \%$ CAD when compared to the normal diet fed rats at the 12th week of feeding (Table 3).

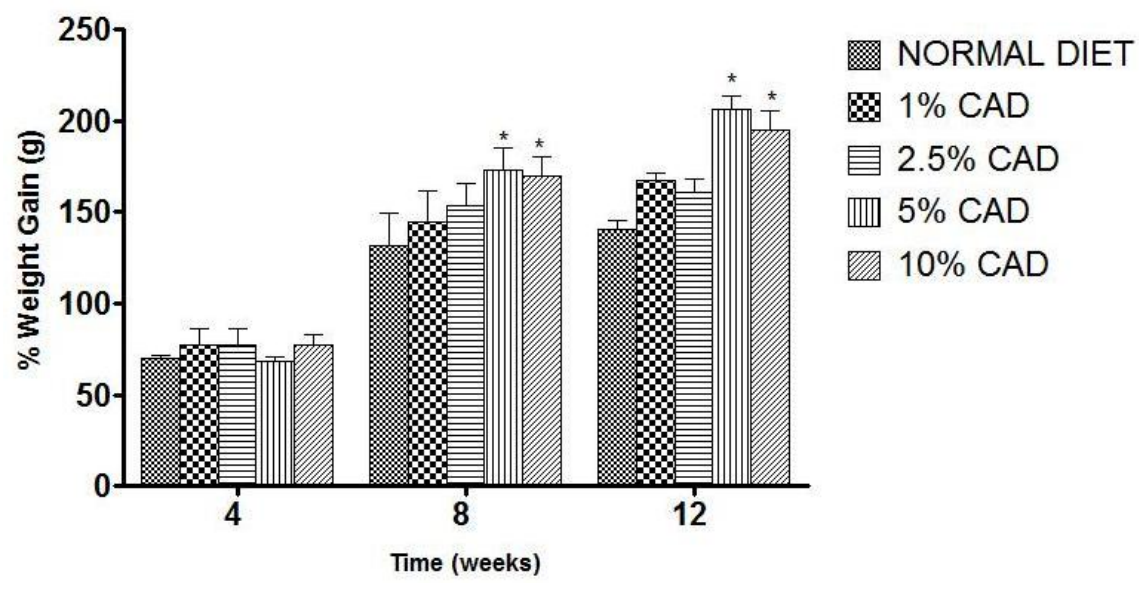

Fig. 1. Effect of CAD on the percentage weight gain in rats at 4, 8 and 12 weeks

Values are expressed as mean $\pm S E M, n=6$. The level of significance was expressed as * $p<0.05$ compared with the normal diet and the CAD groups. $C A D=$ Cnidoscolus aconitifolius-supplemented diet 
Table 1. Effect of Cnidoscolus aconitifolius-supplemented diet on hematological indices in rats at 4 weeks

\begin{tabular}{|c|c|c|c|c|c|}
\hline Parameters & Normal diet & CAD 1\% & CAD $2.5 \%$ & CAD 5\% & CAD 10\% \\
\hline White Blood Cells $\left(10^{3} \mathrm{~mm}^{-1}\right)$ & $2068.75 \pm 189.40$ & $2068.75 \pm 101.74$ & $2150.00 \pm 106.07$ & $2937.50 \pm 129.7$ & $1912.50 \pm 201.43$ \\
\hline Red Blood Cells $\left(10^{6} \mathrm{~mm}^{-1}\right)$ & $6.01 \pm 0.24$ & $5.59 \pm 0.15$ & $6.26 \pm 0.46$ & $6.51 \pm 0.59$ & $5.61 \pm 0.22$ \\
\hline Packed Cell Volume (\%) & $37.13 \pm 1.56$ & $33.63 \pm 2.83^{*}$ & $37.63 \pm 0.83$ & $34.00 \pm 3.05^{*}$ & $35.00 \pm 1.51$ \\
\hline Platelets & $54750.00 \pm 2780.14$ & $100250.00 \pm 16172.89^{*}$ & $87250.00 \pm 5764.46^{* *}$ & $113125.00 \pm 13301.60$ & $67375.00 \pm 17413.33$ \\
\hline Hemoglobin concentration (gm 100-1mm) & $11.55 \pm 0.459$ & $10.53 \pm 0.87$ & $12.35 \pm 0.33$ & $11.11 \pm 0.99$ & $11.44 \pm 0.66$ \\
\hline Mean Corpuscular Hemoglobin (pg) & $9.63 \pm 0.33$ & $9.57 \pm 0.51$ & $9.97 \pm 0.53$ & $8.87 \pm 1.28$ & $8.87 \pm 1.23$ \\
\hline Mean Corpuscular Hemoglobin Conc. (\%) & $15.59 \pm 0.54$ & $15.67 \pm 0.27$ & $16.41 \pm 0.22$ & $16.41 \pm 0.22$ & $16.31 \pm 0.26$ \\
\hline Mean Corpuscular Volume $\left(\mathrm{m}^{-3}\right)$ & $30.88 \pm 0.20$ & $30.59 \pm 1.96$ & $30.36 \pm 1.48$ & $27.18 \pm 4.01$ & $31.17 \pm 0.42$ \\
\hline Neutrophils (\%) & $18.25 \pm 1.45$ & $22.25 \pm 0.63$ & $22.00 \pm 1.85$ & $22.00 \pm 1.93$ & $20.25 \pm 1.39$ \\
\hline Lymphocytes (\%) & $78.50 \pm 1.16$ & $75.50 \pm 0.52$ & $74.00 \pm 1.95$ & $74.25 \pm 1.45$ & $75.25 \pm 1.41$ \\
\hline Monocytes(\%) & $1.75 \pm 0.25$ & $1.75 \pm 0.48$ & $1.75 \pm 0.25$ & $1.75 \pm 0.48$ & $1.75 \pm 0.25$ \\
\hline Eosinophils(\%) & $0.75 \pm 0.32$ & $0.25 \pm 0.14$ & $1.23 \pm 0.24$ & $0.88 \pm 0.24$ & $1.38 \pm 0.13$ \\
\hline
\end{tabular}

Table 2. Effect of Cnidoscolus aconitifolius-supplemented diet on hematological indices in rats at 8 weeks

\begin{tabular}{|c|c|c|c|c|c|}
\hline Parameters & Normal diet & CAD 1\% & CAD 2.5\% & CAD 5\% & CAD 10\% \\
\hline White Blood Cells $\left(10^{3} \mathrm{~mm}^{-1}\right)$ & $2262.50 \pm 289.67$ & $3962.50 \pm 265.66^{* *}$ & $4075 \pm 116.37^{* *}$ & $2887.5 \pm 331.89$ & $3212.50 \pm 267.99$ \\
\hline Red Blood Cells $\left(10^{6} \mathrm{~mm}^{-1}\right)$ & $5.79 \pm 0.63$ & $4.40 \pm 0.32$ & $5.77 \pm 0.42$ & $4.58 \pm 0.38$ & $5.55 \pm 0.79$ \\
\hline Packed Cell Volume (\%) & $34.50 \pm 3.66$ & $26.50 \pm 2.22$ & $34.50 \pm 3.12$ & $27.75 \pm 2.14$ & $32.25 \pm 4.44$ \\
\hline Platelets & $89000.00 \pm 7245.69$ & $70750.00 \pm 10419.33^{*}$ & $106750.00 \pm 6169.48$ & $86750 \pm 6223.28$ & $95000.00 \pm 7560.86$ \\
\hline Hemoglobin concentration (gm 100-1mm) & $11.63 \pm 1.39$ & $8.90 \pm 0.67$ & $11.55 \pm 1.03$ & $9.15 \pm 0.75$ & $10.75 \pm 1.58$ \\
\hline Mean Corpuscular Hemoglobin (pg) & $19.99 \pm 0.83$ & $20.35 \pm 0.58$ & $19.95 \pm 0.51$ & $20.02 \pm 0.47$ & $19.30 \pm 0.31$ \\
\hline Mean Corpuscular Hemoglobin Conc. (\%) & $33.58 \pm 0.56$ & $33.64 \pm 0.68$ & $33.49 \pm 0.34$ & $32.93 \pm 0.29$ & $33.14 \pm 0.63$ \\
\hline Mean Corpuscular Volume $\left(\mathrm{m}^{-3}\right)$ & $59.54 \pm 0.38$ & $60.63 \pm 2.62$ & $59.58 \pm 1.75$ & $60.82 \pm 1.84 /$ & $58.23 \pm 0.38$ \\
\hline Neutrophils (\%) & $32.75 \pm 2.66$ & $42.00 \pm 1.23^{* *}$ & $30.25 \pm 1.49$ & $58.5 \pm 2.39$ & $35.75 \pm 5.92$ \\
\hline Lymphocytes (\%) & $64.75 \pm 2.63$ & $55.70 \pm 0.85$ & $66.00 \pm 1.78$ & $1.00 \pm 0.00$ & $60.50 \pm 5.97$ \\
\hline Monocytes (\%) & $1.25 \pm 0.25$ & $1.25 \pm 0.25$ & $2.25 \pm 0.25$ & $1.20 \pm 0.63$ & $2.25 \pm 0.25$ \\
\hline Eosinophils (\%) & $0.75 \pm 0.48$ & $1.00 \pm 0.41$ & $1.50 \pm 0.45$ & - & $1.50 \pm 0.65$ \\
\hline
\end{tabular}


Table 3. Effect of Cnidoscolus aconitifolius-supplemented diet on hematological indices in rats at 12 weeks

\begin{tabular}{|c|c|c|c|c|c|}
\hline Parameters & Normal diet & CAD 1\% & CAD 2.5\% & CAD 5\% & CAD $10 \%$ \\
\hline White Blood Cells $\left(10^{3} \mathrm{~mm}^{-1}\right)$ & $5037.50 \pm 184.14$ & $4737.50 \pm 477.57$ & $4700.00 \pm 381.34$ & $4600.00 \pm 852.45$ & $4787.50 \pm 530.87$ \\
\hline Red Blood Cells $\left(10^{6} \mathrm{~mm}^{-1}\right)$ & $6.38 \pm 0.39$ & $6.15 \pm 0.69$ & $6.16 \pm 0.52$ & $5.90 \pm 0.34$ & $6.93 \pm 0.48$ \\
\hline Packed Cell Volume (\%) & $37.00 \pm 1.87$ & $35.75 \pm 4.05^{*}$ & $36.75 \pm 2.93^{*}$ & $35.50 \pm 2.10$ & $40.25 \pm 2.96^{*}$ \\
\hline Platelets & $130500.00 \pm 12086.49$ & $164250.00 \pm 3145.76$ & $161750.00 \pm 11535.27$ & $150000.00 \pm 12062.34$ & $157500.00 \pm 14361.41$ \\
\hline Hemoglobin concentration (gm 100-1mm) & $12.60 \pm 0.66$ & $12.03 \pm 1.38$ & $12.33 \pm 0.89$ & $11.88 \pm 0.60$ & $13.75 \pm 0.86$ \\
\hline Mean Corpuscular Hemoglobin (pg) & $19.81 \pm 0.39$ & $19.54 \pm 0.31$ & $20.08 \pm 0.52$ & $20.16 \pm 0.49$ & $19.86 \pm 0.16$ \\
\hline Mean Corpuscular Hemoglobin Conc. (\%) & $34.05 \pm 0.34$ & $33.65 \pm 0.52$ & $33.59 \pm 0.28$ & $33.50 \pm 0.47$ & $34.26 \pm 0.81$ \\
\hline Mean Corpuscular Volume (m-3)MCV & $58.18 \pm 0.90$ & $58.08 \pm 0.92$ & $59.76 \pm 1.44$ & $60.18 \pm 1.84$ & $58.08 \pm 1.56$ \\
\hline Neutrophils (\%) & $31.75 \pm 3.52$ & $27.25 \pm 2.72$ & $28.00 \pm 1.35$ & $29.75 \pm 2.10$ & $29.25 \pm 3.23$ \\
\hline Lymphocytes (\%) & $65.25 \pm 3.64$ & $69.00 \pm 2.97$ & $68.50 \pm 1.56$ & $68.00 \pm 1.47$ & $68.25 \pm 3.43$ \\
\hline Monocytes(\%) & $2.00 \pm 0.41$ & $1.75 \pm 0.25$ & $2.25 \pm 0.25$ & $1.75 \pm 0.48$ & $1.50 \pm 0.29$ \\
\hline Eosinophils(\%) & $0.20 \pm 0.25$ & $2.00 \pm 0.71^{*}$ & $1.25 \pm 0.25$ & $1.25 \pm 0.48$ & $1.00 \pm 0.41$ \\
\hline
\end{tabular}



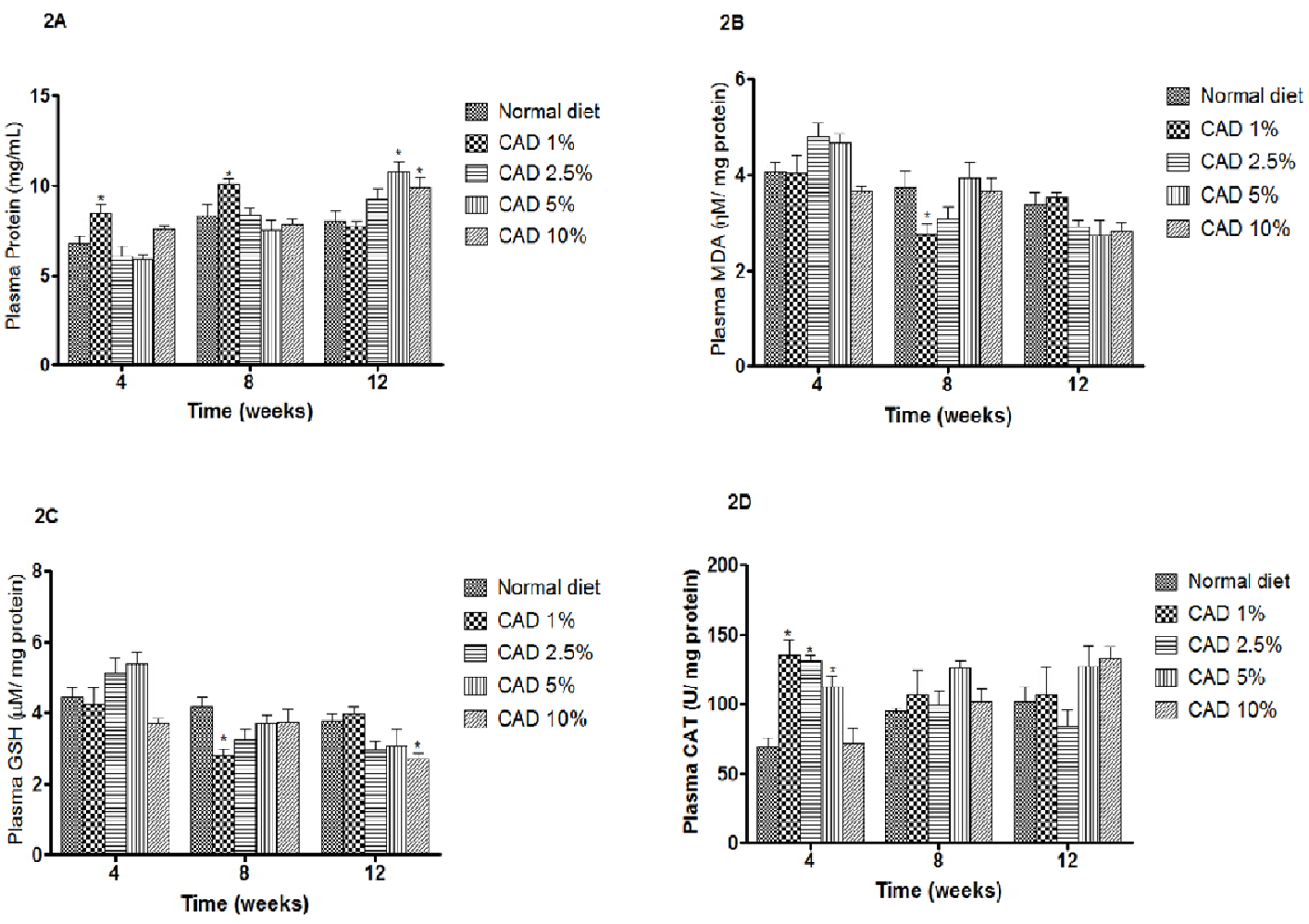

Fig. 2 (A, B, C \& D). Effect of CAD on oxidative activity in rats

Values are expressed as mean \pm SEM, $n=4$. The level of significance was expressed as ${ }^{*} p<0.05$ compared with the normal diet and the CAD groups. $C A D=$ Cnidoscolus aconitifolius-supplemented diet
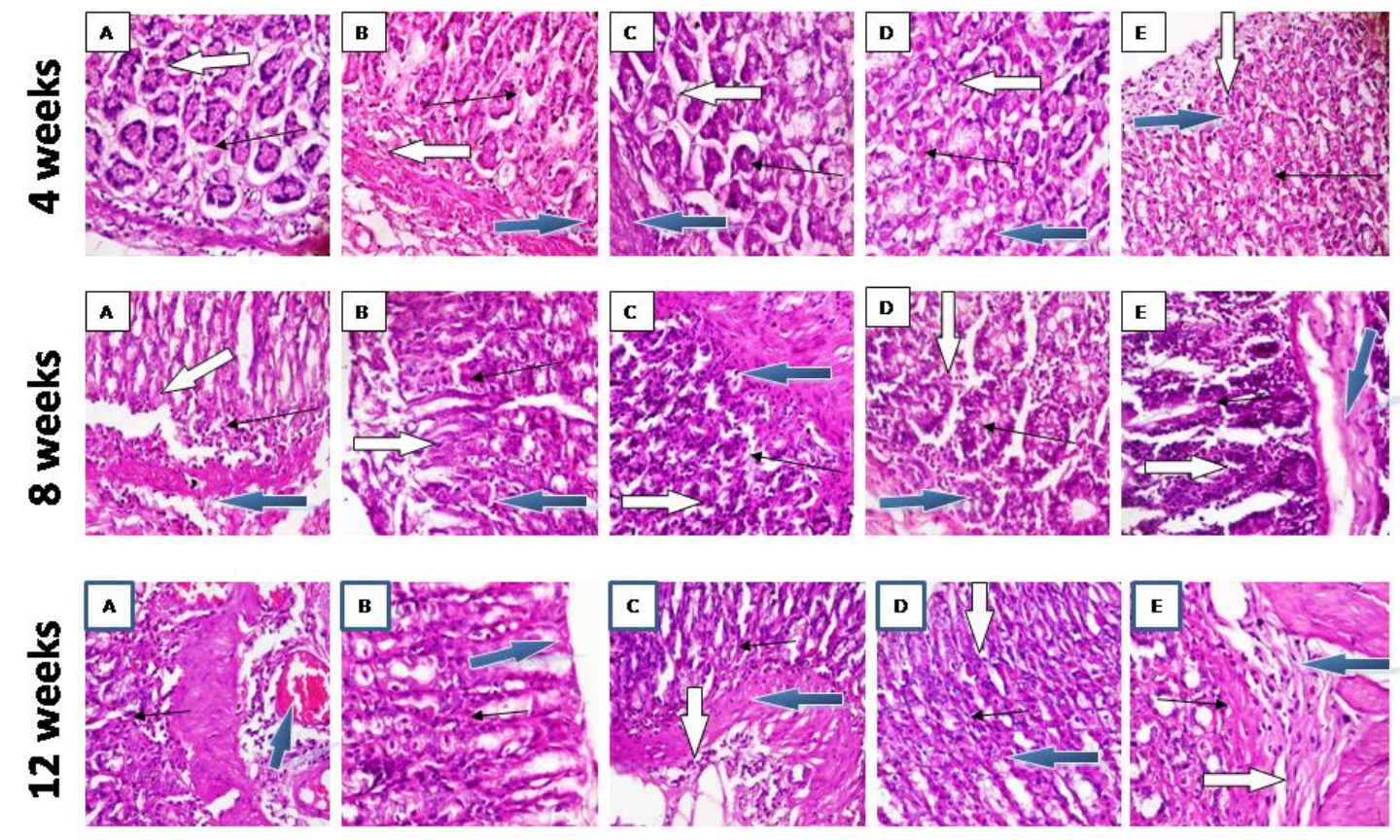

Plate 1. Photomicrograph of stomach in rats fed with Cnidoscolus aconitifolius-supplemented diet (CAD) at 4, 8 and 12 weeks stained with H\&E (presented at X400 magnification) 
Histopathology analyses of the rats fed Cnidoscolus aconitifolius-supplemented diet and the normal fed rats at 4 weeks, 8 weeks and 12 weeks: Photomicrography of the stomach sections using Hematoxylin and Eosin (H\&E) staining in the normal and experimental rats shows the mucosa epithelial cells layer without sloughing and well preserved (white arrow), the mucosa layer show no infiltration of the lamina propriaand gastric glands (slender arrow), and the submucosal layers appear normal and are not infiltrated by any inflammatory cells (blue arrow) at 4 weeks of feeding with CAD (Plate 1). At 8 weeks of feeding the normal and experimental rats appears normal for $1 \%$ CAD except for the rats fed with $2.5 \%, 5 \%$, and $10 \%$ CAD which shows a slight unpreserved mucosa epithelial cells layer (white arrow). For the rats fed for 12 weeks, it shows the mucosa epithelial cells layer without sloughing and well preserved (white arrow), the mucosa layer show no infiltration of the lamina propria and gastric glands (slender arrow), and the submucosal layers appear normal and are not infiltrated by any inflammatory cells (blue arrow) (Plate 1).

\section{DISCUSSION}

Cnidoscolus aconitifolius-supplemented diet (CAD) fed to rats in this study was shown to improve hematological indices, reduces weight loss and oxidative stress, and also maintains the histology of the stomach wall, depicting a possible hematoprotective and gastroprotective effects. Blood disorders are considered a major hematopoietic disorder related to anemia, thelassemia, polycythemia vera, leukemia, etc. which are major conditions that reduces the quality of life of suffer [29,30,31,32]. Diets rich in certain types of vegetables have been previously shown to reduce the risk of developing hematopoietic dysfunctions.

Cnidoscolus aconitifolius-supplemented diet fed to the rats for up to 12th weeks was seen to show significant weight gained. Increase in body weight is an index for acceptability of the food formulation in rodents. An earlier study on $C$. aconitifolius revealed the presence of desirable nutritional factors that can serve as source of ingredients for functional foods [8].

Various studies have shown the effect of oxidative stress in the pathogenesis of hematopoietic diseases in humans. Phytochemical constituents are responsible for medicinal activity of plant species. Preliminary phytochemical analysis reveals large number of flavonoids, phytate, saponin, alkaloid, tannins and cyanogenic glycosides present in leaf extract of Cnidoscolus aconitifolius [33,34,35]. The result of these phytochemicals suggests that the plant possesses potential anti-inflammatory, antimicrobial and antioxidant properties $[33,34,35]$. Natural antioxidants mainly come from plants in the form of phenolic compounds, such as flavonoids, phenolic acids, tocopherols. The plant also possesses good proportion of vitamin $A, B, C$ \& $E$. Vitamin A effectively mediate normal vision, gene expression, growth and immune function by its maintenance of epithelial cell functions [36]. Vitamin $C$ also is a potent antioxidant that facilitates the transport and uptake of non-heme iron at the mucosa, the reduction of folic acid intermediates and the synthesis of cortisol. Its deficiency includes fragility to blood capillaries gum decay, scurvy [37]. Vitamin $E$ is a powerful antioxidant which helps to protect cells from damage by free radicals and it is vital for the formation and normal function of red blood cells and muscles [36]. Adequate supply of dietary antioxidants may prevent or delay diabetes complications including renal and neural dysfunction by providing protection against oxidative stress [38]. The B vitamins are essential for growth, development, and a variety of other bodily functions. They play a major rolein the activities of enzymes [39] experimental evidences supporting the free radical scavenging capacity of some phytochemicals (such as Saponin, flavonoids and tannins) contained in the plant help in the prevention of oxidative damage in the body system $[40,41,35]$.

Malondialdehyde (MDA) is an indicator of lipid peroxidation which also indicates the level of hematopoietic decline in blood cells was reported in this study. Cnidoscolus aconitifolius supplemented diet ameliorates MDA activity at $8^{\text {th }}$ weeks of feeding. Study on $C$. aconitifolius reveal the ameliorative potential on MDA activity (index of lipid peroxidation) $[42,43]$. Similarly, the activity of saponins present in the leaf may be responsible for the potential reduction of lipid peroxidation activity as saponins have been seen to exhibit antioxidant activity by reducing the lipid hydroperoxides level [44].

The glutathione (GSH) is a water-soluble tripeptide composed of the amino acids glutamine, cysteine, and glycine which plays a role in the detoxification of a variety of 
electrophilic compounds and peroxides via catalysis by glutathione S-transferases (GST) and glutathione peroxidases [45]. Glutathione is a major endogenous antioxidant produced by the cells and participates in neutralization of free radicals and reactive oxygen species [46]. From the result in this study, glutathione activity was observed to decrease at 4th week and 12th week of feeding with Cnidoscolus aconitifoliussupplemented diet. This shows that Cnidoscolus aconitifolius leaf does not provide much ameliorative potentials against oxidative stress when not extracted in ethanol or methanol. Although the extraction of Cnidoscolus aconitifolius leaf in either ethanol or methanol was previously reported to have ameliorative potentials against oxidative stress and also a possible treatment against tissue damage [47]. The decrease in glutathione activity could be due to supplementation with diet in raw feeding and when not extracted.

Catalase (CAT) is an enzymatic antioxidant. It is a component of the body antioxidant defense systems which are involved in detoxification of free radicals formed during oxidative stress. CAT is a homoprotein, localized in the peroxisomes or the micro-peroxisomeswhich catalases the decomposition of $\mathrm{H}_{2} \mathrm{O}_{2}$ to $\mathrm{H}_{2} \mathrm{O}$ and $\mathrm{O}_{2}$ and thus protecting the cell from oxidative damage by $\mathrm{H}_{2} \mathrm{O}_{2}$ and $\mathrm{OH}$ [48]. This study shows that catalase activity increases at 4th week of feeding with Cnidoscolus aconitifolius-supplemented diet. It shows a potential ameliorative effect against oxidative stress [42]. The increase in Catalase activity in Cnidoscolus aconitifoliussupplemented diet may be attributed to free radical scavenging activities of Cnidoscolus aconitifolius leaf. These antioxidant properties of the leaf can be attributed to the presence of flavonoids and vitamins $\mathrm{C}$ and $\mathrm{E}$ in the plant known to possess antioxidant activities $[49,50,43,35]$.

Report from literature showed that blood indices are very significant for the assessment of the nutritive component of a given ration [51,52]. Cnidoscolus aconitifolius leaf was initially reported by various researchers to possess high nutritive components, working as a blood purifier, increases blood circulation, and also reduces the rate of heart disease and cholesterol [53,54,55]. From the report on this study, it was investigated that at 4 weeks, the PCV and Platelet increases, at 8 weeks there was a decrease in WBC and neutrophils with an increase in platelet, and at 12 weeks the PCV and basophils increases when fed with Cnidoscolus aconitifolius-supplemented diet. Packed cell volume is a measure of erythrocytes in the blood and increment connotes production of red blood cells and in turn an increase in blood volume [7]. It has been reported that hematological indices give insight into the production potential and help to monitor and evaluate incidence of diseases [56,57]. The increase in these parameters could be attributed to their phytochemical contents.

The histopathology study reveals well preserve gastric wall architecture with no serious damage to the tissues underlying them. A report on the effect of aqueous extract of Cnidoscolus aconitifolius in a rat model reveals a possible treatment in lesions on kidney, liver, and colon when the histopathological analysis was determined [58]. Direct consumption of Cnidoscolus aconitifolius leave could also protect the gastric wall architecture if taken moderately per time.

\section{CONCLUSION}

Our findings showed that the leaves of Cnidoscolus aconitifolius consist of useful antioxidant compounds, which suggest that it exhibit reversal effects on oxidative stress and improves hematologic parameters thus making the plant leaves a good source of natural antioxidants and blood boosters. These findings show that Cnidoscolus aconitifolius is a promising plant for the prevention of diseases due to its rich phytochemical compounds and also could prove a potential hematoprotective and gastroprotective effects.

\section{ETHICAL APPROVAL}

All procedures used for the experimental animals were in accordance with the guidelines of the University of Ibadan Animal Ethical Committee 2017/2018.

\section{COMPETING INTERESTS}

Authors have declared that no competing interests exist.

\section{REFERENCES}

1. Liu RH. Health benefits of fruit and vegetables are from additive and synergistic combinations of phytochemicals. The American Journal of Clinical Nutrition. 2003;78(3):517S-520S. 
2. Liu $\mathrm{RH}$. Health-promoting components of fruits and vegetables in the diet. Advances in Nutrition (Bethesda, Md.). 2013;4(3):384S-92S

3. Ou B, Huang D, Hampsch-Woodill M, Flanagan JA, Deemer EK. Analysis of antioxidant activities of common vegetables employing oxygen radical absorbance capacity (ORAC) and ferric reducing antioxidant power (FRAP) assays: A comparative study. Journal of Agricultural and Food Chemistry. 2002;50(11):3122-3128.

4. Shetty AA, Magadum S, Managanvi K. Vegetables as sources of antioxidants. Journal of Food and Nutritional Disorders. 2013;2(1):2.

5. Higgins JM. Red blood cell population dynamics. Clinics in Laboratory Medicine. 2015;35(1):43.

6. Yakubu MT, Akanji MA, Oladiji AT, Olatinwo AO, Adesokan AA, Oyenike M, Yakubu RN, Bamidele RM, Owoyele V, Sunmonu TO, Ajao MS. Effect of Cnidoscolous aconitifolius leaf extract on reproductive hormones of female rats. Iranian Journal of Reproductive Medicine. 2008;3(6):149-155.

7. Adebayo AH, Aliyu R, Gatsing D, Garba $\mathrm{IH}$. The effects of ethanolic leaf extract of Commiphora africana (Buseraceae) on lipid profile in rats. International Journal of Pharmacology. 2006;2:618-622.

8. Aye PA. Effect of processing on the nutritive characteristics, anti-nutritional factors and functional properties of Cnidoscolus aconitifolius leaves (lyana ipaja). American Journal of Food and Nutrition. 2012;2(4):89-95.

9. Oyagbemi AA, Odetola AA, Azeez OI. Ameliorative effects of Cnidoscolus aconitifolius on anaemia and osmotic fragility induced by protein energy malnutrition. African Journal of Biotechnology. 2008;7(11):1721-1726.

10. Adeniran OI, Olajide OO, Igwemmar NC, Orishadipe AT. Phytochemical constituents, antimicrobial and antioxidant potentials of tree spinach [Cnidoscolus aconitifolius]. J. Medicinal Plants Research. 2013;7(19):1317-1322.

11. Berkelaar D. Chaya. Echo Technical Note; 2006.

12. Orech FO, Akenga T, Ochora J, Friis $H$, Aagaard-Hansen. Potential toxicity of some traditional leafy vegetables consumed in Nyang'oma Division, Western
Kenya. African Journal of Food Agriculture, Nutrition and Development. 2005;5(1):113.

13. Adanlawo IG, Elekofehinti OO. Proximate analysis, mineral composition and amino acid composition of Cnidoscolus aconitifolius leaf. Advances in Food and Energy Security. 2012;2:17-21.

14. Sarmiento-Franco L, McNab JM, Perason RA, Belmar-Cassa R. Performance of boilers fed on diets containing different amounts of chaya (Cnidoscolus aconitifolius) leaf meal. Tropical Animal Health and Production. 2002;34(3):257269.

15. Awobajo FO, Olatunji-Bello II, Obilade TT, Odugbemi TO. Knowledge of the nutritional and medicinal use of some vegetables among a cross section of market women in two major food markets in Lagos State, South-West Nigeria. Pakistan Journal of Nutrition. 2010;9(3):216-221.

16. Kuti JO, Torres ES. Potential nutritional and health benefits of the spinach. In J. Jarick (Ed). Progress in New Crops. ASHS Press, Arlington, VA. 1996;516-520.

17. Oloyede GK, Onocha PA, Soyinka J, Oguntoku O, Thonda E. Phytochemical screening, antimicrobial and antioxidant activities of four Nigerian medicinal plants. Annals of Biological Research. 2010;1(2):114-120.

18. Mordi JC, Akanji MA. Phytochemical screening of the dried leaf extracts of Cnidoscolus aconitifolius and associated changes in liver enzymes induced by its administration in wistar rats. Current Research Journal of Biological Sciences. 2012;4(2):153-158.

19. Ekeleme UG, Nwachukwu NC, Ogodo AC, Nnadi CJ, Onuabuchi IA, Osuocha KU. Phytochemical screening and antibacterial activity of Cnidoscolus aconitifolius and associated changes in liver enzymes in wistar rats. Australian Journal of Basic and Applied Sciences. 2013;7(12):156-162.

20. Awoyinka OA, Balogun IO, Ogunnowo AA. Phytochemical screening and in vitro bioactivity of Cnidoscolus aconitifolius (Euphorbiaceae). Journal of Medicinal Plants Research. 2007;1(3):63-65.

21. Onasanwo SA, Oyagbemi $A A$, Saba AB. Anti-inflammatory and analgesic properties of the ethanolic extract of Cnidoscolus aconitifolius in rats and mice. J. Basic Clin Physiol Pharmacol. 2011;22(12):37-41. 
22. Benson HJ, Gunstream SE, Talaro A, Tolaro KP. Anatomy and physiology. Laboratory textbook. WMC Brown Publisher Dubuque IOWA; 1989.

23. Jain NC. Essentials of veterinary hematology. Lea and Febiger Publishers Malvern, Pennsylvania; 1993.

24. Lamb GN. Manual of veterinary laboratory technique. CIBA-GEIGY. 1981;96-107.

25. Nagababu E, Rifkind JM, Sesikeran B, Lakshmaiah N. Assessment of antioxidant activity of eugenol in vitro and in vivo. Methods Mol Biol. 2010;610:165-180.

26. Jollow DJ, Mitchel JR, Zampaglione N, Gilete JR. Bromobenzene induced liver necrosis: Protective role of glutathione and evidence for 3, 4 bromobenzene oxide as the hepatotoxic metabolite. Pharmacology. 1974;1:151-169.

27. Goth JA. Simple method for determination of serum catalase activity and revision of reference range. Clinica Chimica Acta. 1991;196(2-3):143-151.

28. Liu A, Zhao X, Li H, Liu Z, Liu B, Mao X, Guo L, Bi K, Jia Y. 5Hydroxymethylfurfural, an antioxidant agent from Alpinia oxyphylla Miq improves cognitive impairment in A $\beta 1-42$ mouse model of Alzheimer's disease. International Immunopharmacology. 2014;23(2):719725.

29. Hoffman R, Edward J, Benz (Jr.), Leslie E, et al. (Eds.). Hematology: Basic Principles and Practice. $6^{\text {th }}$ Edition; 2015.

30. Geyer H, Scherber R, Kosiorek H, et al. Symptomatic profiles of patients with polycythemia vera: Implications of inadequately controlled disease. Journal of Clinical Oncology. 2016;34:151.

31. Tefferi A, Lasho TL, Guglielmelli $P$. Targeted deep sequencing in polycythemia vera and essential thrombocythemia. Blood Adv. 2016;1(1):21-30.

32. DeBaun MR, Vichinsky EP. Vaso-occlusive pain management in sickle cell disease. Waltham, M.A. Accessed. 2016;6(21):19.

33. Obichi EA, Monago CC, Belonwu DC. Effect of Cnidoscolus aconitifolius (Family Euphorbiaceae) aqueous leaf extract on some antioxidant enzymes and hematological parameters of high fat diet and streptozotocin induced diabetic wistar albino rats. Journal of Applied Sciences and Environmental Management. 2015;19(1):201-209.

34. Moura LFWG, da Silva Neto JX, Lopes TDP, Benjamin SR, Brito FCR, Magalhaes
FEA, Florean EOPT, de Sousa DOB, Guedes MIF. Ethnobotanic phytochemical uses and ethnopharmacological profile of genus Cnidoscolus spp. (Euphorbaceae): A comprehensive overview. Biomed Pharmacother. 2019;109:1670-1679.

35. Us Medina U, Millán Linares MDC, Arana Argáez V, Segura-Campos MR. In vitro antioxidant and anti-inflammatory activity of Chaya extracts (Cnidoscolus aconitifolius (Mill.) I.M. Johnst). Nutr Hosp. 2020;37(1):46-55.

36. Lukaski $\mathrm{CH}$. Vitamin and mineral status: Effect on physical performance. Nutrition Research Centre, Grand Forks, North Dakota, USA. 2004;20:632-644.

37. Achikanu CE, Eze-Steven PE, Ude CM, Ugwuokolie OC. Determination of the vitamin and mineral composition of common leafy vegetables in South Eastern Nigeria. International Journal of Current Microbiology and Applied Sciences. 2013;2(11):347-353.

38. Bartlett HE, Eperjesi F. Nutritional supplementation for type 2 diabetes: A systematic review. Ophthalmic and Physiological Optics. 2008;28:503-523.

39. Wu W, Kang S, Zhang D. Association of vitamin B6, vitamin B12 and methionine with risk of breast cancer: A dose response meta-analysis. British Journal of Cancer. 2013;109(7):1926-44.

40. Block $\mathrm{G}$. The data support a role of antioxidants in reducing cancer risk. Nutr. Rev. 2012;50:207-213. In Mordi JC, Akanji MA. Phytochemical screening of the dried leaf extracts of Cnidoscolus aconitifolius and associated changes in liver enzymes induced by its administration in wistar rats. Current Research Journal of Biological Sciences. 1992;4(2):153-158.

41. Hertog MGL, Feskens EJM. Dietary antioxidant flavonoids and risk of coronary heart disease the zutphen elderly study. Lancet. 2012;342:1007-1011. In Mordi JC, Akanji MA. Phytochemical screening of the dried leaf extracts of Cnidoscolus aconitifoliusand associated changes in liver enzymes induced by its administration in wistar rats. Current Research Journal of Biological Sciences. 1993;4(2):153-158.

42. Adaramoye OA, Aluko A. Methanolic extract of Cnidoscolus aconitifolius attenuates renal dysfunction induced by chronic ethanol administration in wistar rats. Alcohol and Alcoholism. 2010;46(1):49. 
43. Ajiboye BO, Oyinloye BE, Agboinghale PE, Ojo OA. Cnidoscolus aconitifolius (Mill.) I.M. Johnst leaf extract prevents oxidative hepatic injury and improves muscles glucose uptake ex vivo. J. Food Biochem. 2019;43(12):13065.

44. Rodrigues HG, Diniz YS, Faine LA, Galhardi CM, Burneiko RC, Almeida JA, Ribas BO, Novlli ELB. Antioxidant effect of saponins: Potentila actions of a soybean flavonoid on glucose tolerance and risk factors for atherosclerosis. Int. J. Food Sci. Nutr. 2005;56:79-85.

45. Townsend G, LaPallo BK, Boulay CB, Krusienski DJ, Frye GE, Hauser CK, Schwartz NE, Vaughan TM, Wolpaw JR, Sellers EW. A novel P300-based braincomputer interface stimulus presentation paradigm: Moving beyond rows and columns. J. Clinical Neurophysiology. 2010;121:1109-1120.

46. Shao HB, Chu LY, Kang CM. Primary antioxidant free radical scavenging and redox signaling pathways in higher plants cells. International Journal of Biological Sciences. 2008;4(1):8.

47. Ngozi A, Christopher O, Ifeoma I, Chinedum E, Kalu I, Chioma O. Ameliorative potentials of methanol fractions of Cnidoscolus aconitifolius on some hematological and biochemical parameters in streptozotocin diabetic rats. Endocrine, Metabolic \& Immune Disorders -Drug Targets (Formerly Current Drug Targes-Immune, Endocrine \& Metabolic Disoreder). 2018;18(6):637-645.

48. Naganuma A, Anderson ME, Meister A. Cellular glutathione as a determinant of sensitivity to mercuric chloride toxicity: Prevention of toxicity by giving glutathione monoester. Biochemical Pharmacology. 1990;40:693-697.

49. Akah PA, Okafor $\mathrm{Cl}$. Blood sugar lowering effect of Vernonia amygdalina in an experimental rabbit model. Phytotherapy Research. 1992;6:171-173.

50. Ong KW, Hsu A, Song L, Huang D, Tan BK. Polyphenols-rich Vernonia amygdalina shows anti-diabetic effects in streptozotocin-induced diabetic rats. Journal of Ethnopharmacology. 2011;133:598-607.

51. Aletor VA, Egberongbe $O$. Feeding differently processed soyabean. Part 2: An assessment of haematological responses in the characteristics, haematology and sepium chemistry of chickens. Die Nahrung. 1992;36:364-369.

52. Agbede JO, Aletor VA. Evaluation of fish meal replaced with leaf protein concentrate from Gliricidia in diets for broiler-chicks. Effect on performance, muscle growth and hematology and serum metabolites. International Journal of Poultry Science. 2003;2(4):242-250.

53. Orellana SL. Indian medicine in highland Guatemala: The pre-Hispanic and colonial periods. University of New Mexico Press, Albuquerque; 1987.

54. Argueta Villamar A. Atlas de las plantas de la medicinatradicional Mexicana 1. 1. Ed. Biblioteca de la medicina tradicional mexicana. Instituto Nacional Indigenista, Mexico, D.F., Mexico; 2013.

55. Ross-Ibarra J, Molina-Cruz A. The ehnobotany of chaya (Cnidoscolus aconofifolius): A nutritious maya vegetable. Journal of Ethnobothany. 2002;56:350364.

56. Karesh WB, Cook RA. Application of veterinary medicine to in-situ conservation. Oryx. 1985;29:244-252.

57. Orheruata AM, Aikhuomobhogbe PU. Hematological and blood biochemical indices of West African Dwarf (WAD) goats vaccinated against pestes de petite ruminant (PPR). African Journal of Biotechnology. 2006;5:743-748.

58. Kuri-García A, Godínez-Santillán RI, Mejía C, Ferriz-Martínez RA, García-Solís P, Enríquez-Vázquez A, García-Gasca T, Guzmán-Maldonado SH, Chávez-Servín $\mathrm{JL}$. Preventive effect of an infusion of the aqueous effect of chaya leaves (Cnidoscolus aconitifolius) in an Aberrant Crypt Foci rat model induced by azoxymethane and dextran sulfate sodium. J Med Food. 2019;22(8):851-860.

(0) 2020 Onasanwo et al.; This is an Open Access article distributed under the terms of the Creative Commons Attribution License (http://creativecommons.org/licenses/by/4.0), which permits unrestricted use, distribution, and reproduction in any medium, provided the original work is properly cited.

Peer-review history:

The peer review history for this paper can be accessed here: http://www.sdiarticle4.com/review-history/55882 